\title{
REPRODUÇÃO ASSISTIDA POST MORTEM E DIREITOS SUCESSÓRIOS
}

\section{Raphael Rego Borges Ribeiro*}

Resumo: Nesta pesquisa, investigamos se devem ser reconhecidos direitos sucessórios aos filhos concebidos por reprodução assistida post mortem (RAPM). Usamos o Direito CivilConstitucional como metodologia e como marco teórico. Observamos que a doutrina se divide sobre a matéria em quatro correntes: (a) pela rejeição de direitos hereditários decorrentes da RAPM, notadamente em homenagem à segurança jurídica; (b) pela admissão somente da vocação sucessória pela via testamentária exclusivamente; (c) pela atribuição de vocação legítima somente se a RAPM for realizada dentro de certo prazo; ou (d) pela atribuição irrestrita de vocação legítima. Concluímos que da RAPM decorrem direitos hereditários irrestritos.

Palavras-chave: Herança; Reprodução Assistida; Sucessão Legítima; Sucessão Testamentária; Prazo de Espera.

\section{POSTHUMOUS ASSISTED REPRODUCTION (PAR) AND INHERITANCE RIGHTS}

Abstract: In this research, I investigated whether should inheritance rights be attributed to PAR-born children. I used the civil-constitutional law as both methodology and theoretical framework. I noticed that the literature is divided into 4 doctrines: (a) rejecting of inheritance rights, especially for legal stability reasons; (b) exclusively accepting testamentary bequeaths in favour of those children; (c) exclusively recognizing intestate succession rights if the PAR is conducted in a certain period of time after the donor's death; (d) unrestrictedly attributing intestate succession rights to PAR-born children. I concluded that the last doctrine best suits the approach I adopted.

Keywords: Inheritance; Assisted Reproduction; Intestate Succession; Testamentary Succession; Wait Time.

\section{INTRODUÇÃO}

A reprodução assistida post mortem (RAPM) consiste na procriação humana que usa material genético de doador já falecido. Trata-se de técnica possibilitada pela criopreservação de gametas, e a extração do material germinativo pode se realizar tanto em vida quanto, em determinadas circunstâncias, após a morte do doador. Apesar de ser mais comum sua prática

\footnotetext{
* Bacharel, Mestre e Doutor em Direito pela Universidade Federal da Bahia. Graduate student e pesquisador no Health Law Centre da University of Ottawa. Professor de Direito Civil da Universidade Federal do Oeste da Bahia.
} 
com esperma, a técnica também pode ser usada com óvulos criopreservados, caso em que será necessária a gestação por substituição.

A realização da RAPM acarreta diversas consequências jurídicas, todavia o legislador brasileiro até o momento se preocupou expressamente apenas com uma circunstância: a presunção de paternidade do marido falecido em relação à criança concebida postumamente, desde que adotada a modalidade homóloga. Por essa razão, diversas questões sobre a temática permanecem em aberto, inclusive: (a) o período durante o qual o procedimento poderá ser utilizado após o falecimento do doador do material genético; (b) as pessoas que poderão ter acesso a ele; e (c) os efeitos sucessórios para a prole gerada de tal maneira. É justamente este último problema que se busca enfrentar no presente trabalho, a partir da seguinte questão orientadora: o filho postumíssimo ${ }^{1}$ deve ser reconhecido como herdeiro do genitor préfalecido? Existem 04 principais correntes doutrinárias que discutem a matéria: aquela que rejeita a vocação hereditária decorrente da RAPM; aquela que entende que somente cabe o chamamento sucessório pela via testamentária; aquela que sustenta que cabe vocação legítima na reprodução post mortem, desde que a concepção póstuma se dê dentro de um prazo de espera decorrido da abertura da sucessão; e aquela que compreende pela atribuição de direitos hereditários à prole postumíssima independentemente do tempo em que esta for gerada.

A presente pesquisa se justifica na medida em que tal questão vem se mostrando altamente controversa na doutrina sucessória brasileira, sendo objeto de profícua produção literária nos últimos anos. Semelhantemente, nas VII e VIII edições das Jornadas de Direito Civil (organizadas pelo Conselho da Justiça Federal), o tema foi intensamente debatido. Nas referidas Jornadas, pudemos apresentar os argumentos que suscitaremos na seção 5 deste artigo, contribuindo para a rejeição de propostas de Enunciado que sugeriam a solução do problema com a aplicação analógica do $\$ 4^{\circ}$ do artigo 1.800 do Código Civil de 2002. Dessa forma, o presente trabalho contribui para a literatura fazendo um levantamento do estado da arte do debate doutrinário, bem como propondo uma abordagem inovadora do tema à luz da metodologia civil-constitucional.

Assim, usaremos o Direito Civil-Constitucional como metodologia: nortearemos a investigação na força normativa da Constituição; realizaremos uma "filtragem constitucional" dos institutos do Direito das Sucessões; buscaremos superar os reducionismos e as abstrações

\footnotetext{
${ }^{1}$ Usaremos "postumíssima" em referência à prole concebida após a morte do genitor, considerando
} 
excessivas do direito sucessório; utilizaremos uma renovada teoria da interpretação, com fins aplicativos, rompendo com o modelo clássico de interpretação formalística baseado na simples subsunção do fato à norma; do mesmo modo, substituiremos o tradicional tecnicismo e o positivismo legislativo pelo personalismo e pela preeminência da justiça sobre a letra do texto legal; semelhantemente, defenderemos a prevalência das situações existenciais em relação às patrimoniais, bem como a prioridade da função dos institutos jurídicos em relação à sua estrutura. Adotaremos como marcos teóricos os autores que defendem o fenômeno da constitucionalização do Direito Civil.

Nosso objetivo geral é fundamentar o reconhecimento de direitos sucessórios à prole postumíssima. Como objetivos específicos, em primeiro lugar, resumidamente delimitaremos a aparente aporia normativa sobre a questão, ressaltando as principais normas constitucionais e infraconstitucionais pertinentes. Em segundo lugar, estudaremos os argumentos doutrinários comumente suscitados para rejeitar a vocação hereditária dos filhos concebidos por RAPM. Em terceiro lugar, analisaremos os posicionamentos favoráveis à vocação sucessória da prole postumíssima pela via testamentária. Em quarto lugar, refletiremos sobre a tentativa de se condicionar os direitos hereditários dos filhos concebidos postumamente ao prazo estabelecido no $\S 4^{\circ}$ do artigo 1.800 do Código Civil de 2002. Por fim, compreenderemos, à luz da Constituição Federal de 1988, as razões pelas quais tais filhos devem ser considerados herdeiros legítimos.

\section{ARGUMENTOS CONTRÁRIOS À EXISTÊNCIA DE VOCAÇÃO HEREDITÁRIA LEGÍTIMA}

Parte dos doutrinadores entendem que o Código Civil de 2002 não ampara a capacidade sucessória do filho concebido após a morte, desconsiderando-o como herdeiro, ainda que reconheça a paternidade do falecido doador de material genético. Nesse sentido, podemos mencionar Ana Maria Maciel Bittencourt Passos (2009, p.78), Maria Helena Machado (2009) e Olga Jubert Gouveia Krell (2005, p.185), além da obra de Caio Mário da Silva Pereira, atualizada por Tânia da Silva Pereira (2007). Observamos dois argumentos principais suscitados para fundamentar a corrente doutrinária ora exposta. Em primeiro lugar, 
o princípio da coexistência entre sucedido e sucessor. Em segundo lugar, a segurança jurídica dos chamados à sucessão no momento em que esta é aberta.

\subsection{O PRINCÍPIO DA COEXISTÊNCIA ENTRE SUCEDIDO E SUCESSOR}

Em primeiro lugar, observamos que a regra geral estabelecida no artigo 1.798 do Código Civil de 2002 exige que o herdeiro esteja vivo ou pelo menos concebido no momento da abertura da sucessão: trata-se do princípio da coexistência entre sucessor e sucedido. Autores que rejeitam a vocação hereditária legítima dos filhos postumíssimos argumentam que, como estes jamais coexistiram com o falecido - nem mesmo na condição de nascituros -, faltaria a eles capacidade sucessória.

Nesse sentido, Maria Helena Diniz (2007, p.503) sustenta que o filho "póstumo não possui legitimação para suceder, visto que foi concebido após o óbito de seu 'pai' genético e por isso é afastado da sucessão legítima”. Ainda nesta linha de argumentação, Flavio Murilo Tartuce Silva e José Fernando Simão (2013, p. 26) aduzem que “para a sucessão legítima, a regra de que a pessoa deva existir não comporta exceções, diferentemente do que ocorre na sucessão testamentária, em que podem ser chamadas a suceder pessoas não concebidas". Por sua vez, Silvio Venosa (2007, p.219) e José Roberto Moreira Filho (2012) compartilham do mesmo entendimento.

Compreendemos que esse argumento não é suficiente para afastar os direitos hereditários da prole postumíssima. Primeiramente, ressaltamos que o preceito de existência do sucessor no momento do falecimento do de cujus não é absoluto e, portanto, não pode ser objeto de fetiche dogmático. A própria lei admite excepciona o princípio da coexistência entre sucessor e sucedido: o artigo 1.799, I do Código Civil de 2002 permite que a prole eventual de pessoa viva seja chamada à sucessão pela via testamentária ${ }^{2}$. Dessa forma, não vemos óbice para relativização dessa norma em outras circunstâncias relevantes, como a que aqui se discute.

\footnotetext{
${ }^{2}$ Destaque-se, no mesmo sentido, que o artigo 1.952 do Código Civil de 2002 estabelece que a substituição fideicomissária só se permite em favor das pessoas não concebidas ao tempo da morte do testador.
} 
Em segundo lugar, destacamos que o princípio da coexistência é estabelecido infraconstitucionalmente, jamais podendo prevalecer se sua aplicação no caso concreto resultar em desrespeito a normas constitucionais. Exclusivamente com base no critério hierárquico para solucionar conflitos normativos, podemos tranquilamente argumentar que o artigo 1.798 do Código Civil de 2002 é insuficiente para, sozinho, embasar o afastamento do direito fundamental à herança da prole postumíssima, bem como o princípio da isonomia entre filhos.

Aqui devemos enfrentar a posição de Mário Luiz Delgado (2004, p.45), para quem na observância estrita ao princípio da coexistência não há qualquer violação aos direitos à herança e ao tratamento isonômico. O referido autor sustenta que o fato de alguém estar na condição de filho não o torna absolutamente legítimo e inafastável da sucessão do pai, na medida em que a lei prevê o instituto da exclusão por indignidade e o da deserdação. Discordamos completamente dos argumentos suscitados pelo referido doutrinador. Os institutos da indignidade e da deserdação têm um fundamento específico: a prática de atos reprováveis, de notória gravidade, contra o de cujus ou, a depender da hipótese, contra pessoas próximas a ele. Trata-se de um critério legítimo, à luz da Constituição, para afastar o direito à herança, ainda que o indigno ou deserdado se trate de filho do morto. Esse critério obviamente não se aplica, nem mesmo analogamente, à RAPM, na medida em que a prole postumíssima presumivelmente não praticou qualquer ato delituoso contra o de cujus, bem como não teve qualquer ingerência em relação ao momento no qual foi concebido.

Por outro lado, a referida corrente doutrinária argumenta que inexiste qualquer desrespeito ao princípio da igualdade dos filhos, consagrado na Constituição Federal de 1988. Neste sentido, Valéria Cardin e Andryelle Camilo (2009, p.133) esclarecem que, para os defensores desta teoria, "este princípio preceitua que sejam tratados igualmente os iguais e desigualmente os desiguais. No caso das inseminações post mortem, há uma absoluta disparidade com a concepção ordinária, que ocorre antes da morte de um dos genitores”. Discordamos desse raciocínio, na medida em que, com base na doutrina de Celso Antônio Bandeira de Mello (2011, p.18), acreditamos não haver qualquer correlação lógica entre o critério desequiparador escolhido (momento da concepção) e a desigualdade de tratamento em função dele conferida (afastamento dos direitos hereditários). Semelhantemente, ainda de 
acordo com Bandeira de Mello, mesmo que houvesse essa correlação, ela seria incompatível com os interesses prestigiados na Constituição Federal.

\subsection{A VIOLAÇÃO À SEGURANÇA JURÍDICA}

Em segundo lugar, parcela da doutrina brasileira rejeita os efeitos sucessórios da reprodução assistida post mortem com base nos valores da certeza, previsibilidade e segurança jurídica (que se encontram consagrados no art. $5^{\circ}$, XXXVI da Constituição Federal). Por força do droit de saisine, positivado no artigo 1.784 do Codex, as pessoas vocacionadas à sucessão se tornam, no exato momento em que esta é aberta, qualitativamente e quantitativamente titulares de direitos sucessórios adquiridos. Segundo a corrente doutrinária em comento, eventuais direitos hereditários decorrentes da RAPM violariam a estabilidade das relações sociais, tumultuando a situação jurídico-econômica dos sucessores que foram investidos com tal título no instante da morte do de cujus. Neste sentido, se os herdeiros originalmente chamados a suceder forem descendentes do falecido, as suas quotas inevitavelmente diminuirão com a atribuição de quinhão hereditário a um novo filho gerado postumamente - o mesmo monte será dividido entre mais pessoas. Por outro lado, se o herdeiro inicialmente vocacionado for ascendente ou colateral do falecido, o respeito à ordem de chamamento à herança - que segue o princípio de que a classe mais próxima exclui a mais remota - fará com que ele perca inteiramente o seu quinhão em detrimento da prole concebida post mortem.

O direito adquirido é uma das facetas da segurança jurídica, relacionando-se intimamente com a certeza e a estabilidade, institutos indispensáveis à paz social, que tem por escopo a proteção das relações jurídicas já consolidadas. Desse modo, Ana Caroline Oliveira Montalbano (2012, p.21) indaga "se a inseminação post mortem não colocaria em risco todo o sistema jurídico, principalmente da sucessão, ao dar direitos ao embrião em detrimento das pessoas já existentes”. Neste mesmo sentido, Flávia Brasileiro (2008) questiona a respeito da situação dos demais herdeiros: "permaneceriam na eterna incerteza (enquanto houver embrião oriundo do de cujus) de eventuais alterações na partilha dos bens, influenciando certamente na sua disposição, contrariando, assim, o princípio da segurança jurídica"? Essa situação de insegurança perduraria enquanto fosse mantida a qualidade dos gametas doados pelo falecido 
- período que pode ultrapassar os 20 anos, com as técnicas mais modernas de criopreservação (LIMA JUNIOR, 2012). Igualmente criticando tal possibilidade, manifestam-se Caroline Schneider e Ellen Carina Mattias Sartori:

Não há dúvida, por conseguinte, de que o direito de herança desse filho gerado post mortem deve ser ponderado com a segurança jurídica e a estabilidade das relações. Não há razoabilidade de voltar a um status quo ante, de uma partilha que foi feita nos moldes da lei, amparada na boa-fé de seus participantes, que em momento algum tiveram qualquer conhecimento da possibilidade dessa concepção post mortem. (SCHNEIDER; SARTORI, 2015, p.537)

Reconhecemos que se trata de questionamento bastante relevante, pois a priori não parece razoável que os herdeiros originalmente chamados à sucessão fiquem indefinidamente à espera de uma eventual alteração no quadro sucessório. Ocorre que a segurança jurídica não é um princípio absoluto, nem mesmo em matéria hereditária. Vemos claramente essa opção legislativa com a positivação da petição de herança, regulamentada entre os artigos 1.824 e 1.828 do Código Civil de 2002, por meio da qual se relativiza a estabilidade das relações jurídicas, supostamente alcançada com o trânsito em julgado da homologação da partilha. $\mathrm{O}$ legislador compreendeu que o direito sucessório do herdeiro preterido prevalecerá sobre a segurança jurídica dos sujeitos que partilharam o patrimônio do morto em detrimento daquele, ainda que tenham agido de boa-fé. Com base no próprio Código Civil, verificamos facilmente que a simples alegação de segurança e estabilidade não é idônea para impedir a correta atribuição de quinhão hereditário a quem é seu legítimo titular. Devemos considerar, ainda, que a petição de herança está subordinada a prazo prescricional, conforme dispõe a Súmula 149 do Supremo Tribunal Federal. Como não há previsão específica para a matéria, aplica-se a regra geral do artigo 205 do Código Civil, qual seja, o prazo de 10 anos. Também é entendimento do STF que o termo inicial do lapso prescricional é a abertura da sucessão. O prazo para ajuizamento da petição de herança, entretanto, está sujeita a todas as causas que suspendem ou interrompem a prescrição, inclusive a não fluência do prazo contra os absolutamente incapazes, nos termos do artigo 198, I do Código Civil de 2002. Com base exclusivamente neste dispositivo legal, ainda que não haja nenhum outro óbice à prescrição, em caso de herdeiro nascituro preterido da partilha, o prazo para ajuizamento da demanda petitória chegará a 26 anos contados do nascimento do sucessor. 
Com base nos fatores acima suscitados, depreendemos que, mesmo em matéria sucessória, a política legislativa é no sentido de priorizar o "justo" em detrimento do "seguro". Acreditamos que a negativa de efeitos sucessórios decorrentes da RAPM exclusivamente com base em critérios de estabilidade se trata de uma anacrônica manifestação do Direito Civil oitocentista, marcado por um fetichismo pela segurança. Com Giselda Hironaka (2006, p.02), aprendemos que a fixação dos juristas pela segurança jurídica decorre de uma tendência de se buscarem as "verdades inteiras", ou seja, padrões imutáveis, perfis definitivos para os institutos jurídicos. Essas "verdades inteiras" são mais seguras na medida em que não dão espaço a reorganizações, remodelações, rearranjos. Ocorre que, quando algo se apresenta de modo repetitivo, encaixado em formulações pré-definidas, não há lugar para se pensar o novo nem para se adequar o tempo. Dessa forma, a mencionada autora denuncia que, quando se adota essa perspectiva - "restrita e fechada, e por isso mesmo segura", acaba-se preferindo "a justiça segura à justiça justa". Ocorre que a doutrina apegada ao modo de pensar do Direito Civil "tradicional" parece se preocupar mais com manter as coisas como supostamente sempre foram do que com transformar o Direito das Sucessões para que se torne mais justo, equitativo, emancipatório e inclusivo. Por ser incompatível com a metodologia adotada pela presente investigação, rejeitamos a postura doutrinária ora discutida. Preferimos o justo ao seguro.

\section{ARGUMENTOS FAVORÁVEIS À VOCAÇÃO HEREDITÁRIA SOMENTE PELA VIA TESTAMENTÁRIA}

Conforme mencionamos na seção 2.1, o Código Civil de 2002 autoriza em seu artigo 1.799, I que o autor da herança disponha por testamento em favor de pessoas que ainda não estejam concebidas no momento da abertura da sua sucessão. Assim, a via testamentária é um modo de se flexibilizar o princípio da coexistência entre sucedido e sucessor. Com base no referido dispositivo, alguns doutrinadores sustentam que a única possibilidade de o filho concebido por RAPM ser chamado à sucessão do seu genitor pré-morto é se este tiver deixado testamento beneficiando a própria prole eventual. Segundo esta corrente, o filho postumíssimo "pode apenas ser herdeiro testamentário, não se encaixando dentre os herdeiros legítimos” (RIGO, 2009). 
Ilustrando a presente corrente doutrinária, observamos que, de acordo com Rolf Madaleno (2013, p.527), a exigência legal de coexistência temporal do sucedido com o herdeiro impede que a criança concebida postumamente seja sucessora legítima. $\mathrm{O}$ mencionado autor defende, entretanto, que há possibilidade de vocação testamentária, na medida em que nesta hipótese "não há exigência dessa coincidência entre a morte e a concepção ou o nascimento com vida, porque o de cujus pode indicar, por testamento, herdeiro ou legatário, filhos ainda não concebidos ao tempo de sua morte". No mesmo sentido, Jesualdo Eduardo de Almeida Junior (2005, p.99) defende a necessidade de cláusula testamentária que institua como herdeiros os filhos póstumos do de cujus. Igualmente, Maria Helena Diniz (2007, p.503) admite que a prole eventual beneficiada em testamento seja a do próprio testador. No mesmo sentido se posicionam Guilherme Calmon Nogueira da Gama (2000, p.732), Fernanda de Borges Henriques (2009) e Juliane Fernandes Queiroz (2001, p.80). Esta última autora sustenta, ainda, que o testamento deverá estabelecer o lapso temporal dentro do qual o material criopreservado poderá ser utilizado.

Dentro desta corrente, alguns autores expressamente reconhecem que haverá vínculo de parentalidade entre o genitor pré-falecido e a prole postumíssima; contudo, entendem que a filiação não é ratio suficiente para o estabelecimento de direitos sucessórios, sendo imprescindível o chamamento por testamento. Ilustrativamente, Guilherme Calmon Nogueira da Gama (2003, p.733) defende especificamente que, se se realizar a reprodução assistida post mortem, a paternidade será estabelecida, mas não para fins de direito sucessório, salvo previsão testamentária em seu favor. Para o mencionado autor, a criança prejudicada poderá pleitear a reparação dos danos materiais que sofrer, em face de sua mãe e dos profissionais que a auxiliaram a procriar.

Assim, com base na responsabilidade civil subjetiva da mulher que resolveu conceber e fazer nascer a criança que não terá qualquer direito sucessório em virtude da morte anterior de seu pai - diante da verdade biológica -, será perfeitamente viável ao filho exigir a reparação do dano patrimonial que, normalmente, consistirá na parte que ele teria direito na herança deixada pelo falecido pai e que foi distribuída entre os herdeiros. Tal não significa que a prática seja estimulada, mas representa a indispensabilidade de serem tutelados e promovidos os melhores interesses da criança, que não deve sofrer sanções diante da conduta espúria ou ilegítima daquele que pretendeu procriar com a consciência de que os danos patrimoniais e, também, extrapatrimoniais se verificariam na pessoa da criança concebida com sêmen do ex-marido (ou ex-companheiro). (GAMA, 2003, p.938) 
A solução proposta pela corrente doutrinária ora exposta não nos parece ser a mais adequada por diversas razões. Em primeiro lugar, no ordenamento jurídico brasileiro, filhos herdam em decorrência do vínculo de parentalidade, independentemente da vontade real do de cujus; se não for o caso de indignidade ou deserdação, herdam mesmo até contra a vontade do falecido, por serem herdeiros necessários. Devemos ainda ressaltar que a Constituição Federal de 1988 pró́be tratamento discriminatório a filhos, e aqui se encaixa o tratamento sucessório, independentemente da sua origem. Parece-nos que, estabelecendo que determinados descendentes não herdam por força de lei e apenas por testamento (se houver), estaríamos inconstitucionalmente retornando aos tempos de "filhos de segunda categoria". Consideramos que a vocação testamentária tem um tratamento normativo muito inferior em relação à vocação legítima. Como recorda Anna Beraldo (2010, p.78), a proteção ao descendente concebido postumamente seria demasiado fragilizada, pois a sua vocação hereditária estaria subordinada às circunstâncias referentes à validade, eficácia, revogação e rompimento do testamento. Além disso, reduzir o filho póstumo à condição de herdeiro testamentário seria afastá-lo da condição de herdeiro necessário, o que poderia causar desrespeito à intangibilidade da sua legítima (SCALQUETTE, 2009). Em outras palavras, ele teria o seu quinhão conduzido ao tratamento legalmente atribuído à metade disponível, podendo se submeter, por exemplo, (a) à clausulação livre do seu quinhão (com inaliebalibilidade, incomunicabilidade ou impenhorabilidade); (b) a eventuais determinações de substituição fideicomissária; (c) à redução de disposições testamentárias; ou (d) ao pagamento da vintena devida ao testamenteiro. Por fim, entendemos que é um contrassenso valorativo subordinar inteiramente a vocação sucessória de herdeiros da classe mais prestigiada de todas, a dos descendentes, à elaboração de testamento em plena sociedade brasileira, na qual reconhecidamente o hábito de testar é tão sem popularidade que, em determinados contextos, chega até mesmo a ser um tabu.

Para além das razões acima expostas, compreendemos que a vocação hereditária da prole postumíssima não é logicamente compatível com o art. 1.799, I do Código Civil de 2002. O referido dispositivo exige que a disposição testamentária deverá ser feita em favor da prole ainda não concebida de pessoas que estejam vivas no momento da abertura da sucessão. O de cujus não poderia beneficiar os próprios filhos, na medida em que obviamente não estará mais vivo no momento do próprio falecimento. Em atenção ao referido empecilho, Giselda Hironaka (2003, p.356) sugere que o testador adote uma via reflexa, qual seja, instituir como 
seus herdeiros os filhos ainda não concebidos de seu cônjuge ou companheiro. Entretanto, acreditamos que esta sugestão, apesar de criativa, não considerou a possibilidade de o cônjuge supérstite reconstituir família com outrem e ter filhos desta pessoa, ou partir para a reprodução heteróloga com material genético de doador anônimo (na popularmente chamada "produção independente"), em ambos os casos abandonando o original projeto parental de reprodução assistida mediante a utilização do material genético doado pelo de cujus. Compreendemos que não há problema algum no benefício testamentário nessas situações, contudo elas não dizem respeito à RAPM, sendo cenários inservíveis para tratar do problema ora investigado.

Com base nos argumentos acima delimitados, depreendemos que os problemas relacionados à atribuição de direitos sucessórios na reprodução póstuma não são suficientemente solucionados com a previsão testamentária instituída em benefício da prole postumíssima. Aderimos assim à corrente doutrinária que entende imperativa a vocação hereditária legítima dos filhos concebidos por RAPM. Estes doutrinadores, contudo, se dividem entre, de um lado, aqueles que sustentam a existência de vocação legítima apenas dentro de um prazo após a abertura da sucessão; e, de outro lado, aqueles que defendem a vocação legítima não subordinada a prazo algum. Analisaremos ambas as fundamentações nas seções seguintes.

\section{A VOCAÇÃO LEGÍtimA SUBORDINADA A UM "PRAZO DE ESPERA DA PROLE EVENTUAL"}

Com a intenção de evitar a insegurança permanente dos coerdeiros no tocante à sua posição jurídica de sucessores e à iminência de diminuição patrimonial, uma corrente doutrinária sugere que, através de uma interpretação analógica, aplique-se à RAPM o prazo de dois anos, contado da abertura da sucessão, que é estabelecido pelo $\$ 4^{\circ}$ do artigo 1.800 do Código Civil de 2002 para a vocação hereditária testamentária atribuída à prole eventual. Desse modo, segundo os defensores desta posição, o filho postumíssimo somente será terá o status de sucessor legítimo caso o procedimento seja realizado com sucesso no biênio sequente à morte do de cujus. Como mencionamos na Introdução, nas VII e VIII Jornadas de Direito Civil (realizadas na sede do Conselho da Justiça Federal respectivamente em 2015 e 
2018), foram reiteradamente apresentadas (e derrotadas) propostas de Enunciado neste sentido.

Ilustrativamente, Eduardo Oliveira Leite (2004, p.27), adotando esta linha de pensamento, recomenda a alteração da redação do artigo 1.798 do Código Civil, para que se acrescente à vocação hereditária ordinária a hipótese das pessoas que nascerem por concepção artificial póstuma até dois anos após a abertura da sucessão. Semelhantemente, Ana Andrade (2007, p.30) sugere uma alteração legislativa na qual seja previsto um prazo para que se permita a realização da concepção post mortem. No mesmo sentido, propõe que, enquanto não se corrigir a omissão legal, a jurisprudência solucione a questão utilizando-se analogicamente do prazo previsto no $\S 4^{\circ}$ do art. 1800 do Código Civil de 2002. No mesmo sentido, Catarina de Luca (2010, p.29) igualmente preconiza a aplicação do referido "prazo de espera", dentro do qual os bens da herança ficam reservados à espera do herdeiro ainda não concebido. Se a concepção não ocorrer, os demais herdeiros do de cujus repartirão entre si o quinhão que caberia à prole eventual frustrada.

Em sua Tese de Doutorado, intitulada "Estatuto da Reprodução Assistida", a professora Ana Claudia Scalquette (2009) também aconselha o reconhecimento dos direitos sucessórios ao filho nascido post mortem, desde que respeitado um determinado lapso temporal, como forma de garantir a segurança jurídica dos demais herdeiros, que não poderão aguardar eternamente o seu eventual nascimento. Diferentemente dos demais autores acima mencionados, a referida doutrinadora propõe que se tome como paradigma o prazo de três anos previsto na Lei de Biossegurança para a destinação de embriões passíveis de utilização na pesquisa com células-tronco embrionárias.

Conforme tivemos a oportunidade de defender nas Jornadas de Direito Civil, rejeitamos veementemente os argumentos acima expostos. Em primeiro lugar, discordamos do emprego da caducidade bienal do direito sucessório da prole eventual, previsto no art. $1.800, \S 4^{\circ}$ do Código Civil, de forma analógica para o caso da procriação artificial póstuma. O referido dispositivo diz respeito à vocação testamentária, e aqui estamos discutindo um eventual prazo para a vocação legítima. Do mesmo modo, a respeito da utilização do prazo previsto no artigo $5^{\circ}$, II da Lei de Biossegurança, entendemos que não é possível sua aplicação analógica, na medida em que a mencionada norma diz respeito a embriões congelados, e não a material genético criopreservado ainda não fecundado. Para ambos os 
casos, devemos recordar que, em conformidade com a mais básica teoria da hermenêutica jurídica, para que o intérprete se valha da analogia é necessário que a hipótese não prevista em lei e a contemplada no texto legal guardem entre si um elemento de identidade essencial, fundamental, ou seja, que se encontre, "num e noutro caso, o mesmo princípio básico e de ser uma só a ideia geradora tanto da regra existente como da que se busca" (MAXIMILIANO, 1965, p.224). Percemos claramente que, na primeira hipótese, o artigo $1.800, \S 4^{\circ}$ do Código Civil diz respeito à vocação testamentária, tendo uma ratio completamente distinta da vocação legítima, o que impede o raciocício por analogia. Do mesmo modo, na segunda hipótese, notamos que a Lei de Biossegurança não guarda qualquer similaridade axiológica com o Direito das Sucessões, sendo igualmente inaplicável o pensamento analógico neste caso.

Por seu turno, Valéria Cardin e Andryelle Camilo (2009, p.134) recomendam que se garanta o direito sucessório da prole eventual do de cujus dentro de um lapso temporal de dez anos, contados da abertura da sucessão, aplicando analogicamente o prazo prescricional da petição de herança. De acordo com as referidas doutrinadoras, sendo concebido o filho póstumo dentro do mencionado período, ele poderá ingressar, através de seu representante legal, com a referida demanda em face dos coerdeiros, para ver judicialmente reconhecido o seu título jurídico de sucessor. Somente o imprescritível direito à filiação seria garantido à criança gerada após uma década do falecimento do genitor. As autoras aduzem que esta não é a melhor resposta, porém pelo menos confere tempo suficiente para que a viúva se submeta à técnica reprodutiva e, ao mesmo tempo, contribui para a estabilidade das relações jurídicas. Mesmo nesse caso, compreendemos que não é possível subordinar o direito sucessório da prole postumíssima à condição de esta ser concebida no lapso de 10 anos referentes à prescrição da petição de herança. Acreditamos seria um contrassenso lógico admitir analogia a um prazo prescricional se este mesmo prazo, conforme estabelecido em lei, não corre em desfavor de absolutamente incapazes, quanto mais em face de quem sequer foi concebido ainda.

Em qualquer hipótese, compreendemos que a referida teoria do "prazo de espera" parece apenas deslocar temporalmente a controvérsia sucessória ora analisada. Ela estabelece certa estabilidade e previsibilidade para os demais envolvidos na sucessão por um (curto) lapso temporal, sem enfrentar diretamente o problema de que, decorrido o prazo sugerido, 
continuará a se admitir uma classe de filhos com tratamento sucessório de segunda categoria, com direitos hereditários recusados exclusivamente em razão do tempo em que foram concebidos. Aqui concordamos com Maria Berenice Dias (2013, p.126), segundo quem “a tentativa de emprestar segurança aos demais sucessores não deve prevalecer sobre o direito hereditário do filho que veio a nascer, ainda que depois de alguns anos". Por tudo quanto expusemos acima, consideramos que, em se reconhecendo a parentalidade do de cujus em relação ao filho postumíssimo, não seja possível condicionar o direito sucessório deste a um prazo de realização da RAPM.

\section{ARGUMENTOS FAVORÁVEIS À VOCAÇÃO LEGÍTIMA. ANÁLISE À LUZ DA TEORIA DOS DIREITOS FUNDAMENTAIS APLICADA AO ART. 5', XXX DA CONSTITUIÇÃO FEDERAL DE 1988}

Em contraposição às insuficientes respostas fornecidas pelas correntes mencionadas anteriormente, há segmento doutrinário que sustenta que o filho concebido por reprodução artificial post mortem tem ampla e irrestrita condição de herdeiro legítimo. Ilustrativamente, Giselda Maria Fernandes Novaes Hironaka (2009, p.59) defende que, realizando-se a procriação póstuma, "operar-se-á o vínculo parental de filiação, com todas as consequências daí resultantes, conforme a regra basilar da Constituição Federal, pelo seu art. 226, §6 incluindo os direitos sucessórios relativamente à herança do pai falecido". Nesse sentido, Regiane Presot (2013) leciona que o argumento basilar desta ideia é que, em primeiro lugar, o direito à filiação existe pelo simples fato de o sujeito ser filho, ainda que este seja indesejado ou inimigo capital do genitor; e, em segundo lugar, a consequência inexorável é do reconhecimento do vínculo de parentalidade, a atribuição da vocação hereditária é imperiosa.

Para a referida corrente doutrinária, o direito constitucional à herança deve ser garantido de maneira isonômica tanto aos filhos já nascidos quando do falecimento do de cujus quanto àqueles que eventualmente ainda nascerão, ainda que concebidos após a morte do genitor (MONTALBANO, 2012). Nesse sentido, Luiz Gavião de Almeida (2003, p.104) defende que "a ligação parental entre o de cujus e o indivíduo vindo de inseminação artificial homóloga é indiscutível, quer tenha ele nascido enquanto vivo ou depois de morto o seu pai”. Segundo o doutrinador, na medida em que o legislador reconhece direitos pessoais ao 
concepturo, não se justifica o afastamento dos seus direitos patrimoniais, especialmente os hereditários. Tal linha de pensamento encontrou acolhimento na III Jornada de Direito Civil, quando se aprovou o Enunciado 267, que determina:

A regra do art. 1798 do Código Civil deve ser estendida aos embriões formados mediante o uso de técnicas de reprodução assistida, abrangendo, assim, a vocação hereditária da pessoa humana a nascer cujos efeitos patrimoniais se submetem às regras previstas para a petição de herança.

Seguindo a ora comentada corrente doutrinária, Maria Berenice Dias (2013, p.125) afirma que é difícil atribuir mais valor a uma ficção jurídica, como a saisine, do que ao princípio constitucional da igualdade assegurada à filiação. A mencionada autora sustenta que há um equívoco na interpretação que confere mais atenção aos direitos de terceiros do que aos da criança gerada nessas circunstâncias; para ela, "nada justifica excluir o direito sucessório do herdeiro por ter sido concebido post mortem". Maria Berenice Dias (2013, p.125) ainda afirma que "sob qualquer ângulo que se enfoque a questão, descabido afastar da sucessão quem é filho e foi concebido pelo desejo do genitor". Por fim, conclui que não é possível condicionar os direitos sucessórios da prole póstuma à existência de testamento, porque todos os filhos pertencem à classe dos herdeiros legítimos e necessários, com direito à herança e à intangibilidade da legítima.

Silmara Chinelato (2004, p.55) entende que a presunção de paternidade estabelecida pelo Código Civil é suficiente para garantir os direitos sucessórios da prole ainda não concebida no momento da abertura da sucessão, notadamente quando associada ao consentimento do de cujus para a realização da inseminação póstuma com utilização do seu material germinativo. Anna Beraldo (2010, p.79) faz referência a doutrinadores que utilizam a conveniência prática, referente à existência de partilha dos bens do de cujus, como fundamento para recusar direitos sucessórios aos filhos concebidos por inseminação post mortem; esta autora afasta veementemente tal argumento, porque, "uma vez nascido o filho, este deve ser protegido".

Bruna Amarijo Coco (2012) afirma que a Constituição de 1988 consagra a pluralidade familiar, tornando descabida a adoção de uma interpretação infraconstitucional que desprestigie a família formada a partir da concepção artificial post mortem. "Ao passo que, ao se reconhecer efeitos pessoais ao concepturo (relação de filiação), não se justifica o plurido de 
afastar os sucessórios decorrentes"; por fim, a autora conclui que "garantindo a lei o vínculo, não se justifica a privação do concebido post mortem de ter legitimação para suceder o de cujus". Por sua vez, Ana Carolina Souza Andrade (2007, p.29) sustenta que a omissão do Código Civil quanto à matéria não significa uma proibição legislativa ao reconhecimento dos direitos sucessórios da prole concebida postumamente. Aplicando o direito à herança e os princípios da igualdade e da pluralidade das entidades familiares em suas reflexões, a autora conclui que os filhos gerados nessas circunstâncias são herdeiros. Entretanto, a referida doutrinadora concede que não se pode deixar de perseguir uma solução jurídica que também contemple os direitos dos coerdeiros, pois estes não poderão ficar eternamente à espera da realização da RAPM.

Em razão das insuficiências teórico-normativas das doutrinas que expusemos nas seções 2, 3 e 4, aderimos à corrente que reconhece irrestritamente os direitos sucessórios decorrentes da RAPM. Nossa contribuição específica para o debate se dá com uma análise da questão à luz da metodologia civil-constitucional.

De acordo com a teoria dos direitos fundamentais, esses direitos têm uma dimensão objetiva, da qual decorre uma "mais-valia jurídica" que reforça sua eficácia normativa (ANDRADE, 2001, p.138). Um desdobramento dessa "mais-valia jurídica" dos direitos fundamentais é a sua eficácia irradiante, o que significa que eles servem de impulsos e diretrizes para a aplicação e a interpretação do direito infraconstitucional (SARLET, 2015, p.153). Nesse mesmo sentido, o direito fundamental tem eficácia normativa direta, devendo ser aplicado tanto quanto possível, ainda que sem interposição (direta ou indireta) do legislador infraconstitucional (GOMES, 2015, p.98). Além disso, cada direito fundamental tem um núcleo essencial, impenetrável, que representa uma competência negativa do Estado: um espaço de proteção sobre o qual os poderes restritivos estatais não podem avançar, sob pena de violação das garantias dos indivíduos. Disposição normativa ou interpretação que viole núcleo essencial de direito fundamental, arbitrariamente negando aplicação desse direito, é essencialmente inconstitucional. A própria ponderação de interesses, quando realizada pelos poderes constituídos com base no princípio da proporcionalidade, deve restringir o mínimo possível o âmbito de proteção dos direitos fundamentais e jamais poderá interferir no núcleo essencial. Do mesmo modo, a "mais valia jurídica" dos direitos fundamentais não exige apenas uma abstenção dos poderes constituídos; dela também decorre 
a imposição ao Estado de um dever geral de efetivação, no sentido da obrigatoriedade da adoção ativa de medidas visando à proteção e ao exercício desses direitos (SARLET, 2015, p.155). Daí também surge o princípio da proibição da proteção deficiente, segundo o qual o Estado deve assegurar um mínimo adequado de proteção normativa aos direitos fundamentais, sendo vedadas omissões legislativas que signifiquem o descumprimento desse dever (ANDRADE, 2001, p.144).

Da dimensão objetiva do direito fundamental à herança, assim como de qualquer outro dispositivo do artigo $5^{\circ}$ da Constituição, decorrem a sua eficácia direta, um dever estatal de efetivação e a proibição da proteção deficiente. Com basse nesses efeitos jurídico-normativos, eliminamos os argumentos que negam os direitos sucessórios decorrentes da RAPM com base na inexistência de disposição do Código Civil nesse sentido. O Codex de 2002 poderia ter disposto sobre a matéria, na medida em que a técnica já estava sendo posta em prática quando da aprovação final do Código no Congresso Nacional; entretanto, o legislador indevidamente permaneceu silente. Ocorre que esse silêncio é inconstitucional: o dever de conformação normativa infraconstitucional não se esgota com a simples edição do livro de Direito das Sucessões do Código Civil de 2002, porém demanda uma regulamentação adequada, sob pena de se configurar a proteção deficiente. Por essa razão, a simples omissão legislativa em relação à prole postumíssima jamais poderia ser utilizada como justificativa para interditar a titularidade do direito fundamental à herança, ainda mais quando isso resulta na proteção deficiente aos direitos sucessórios dos descendentes, uma classe de sucessores particularmente privilegiada pela lei em vigor. Ressaltamos ainda que tratamento sucessório distinto a determinados descendentes é violação frontal da isonomia constitucional, que impede a legislação de tratar alguns filhos como se de segunda categoria fossem. Por outro lado, acreditamos que resolver o problema aplicando acriticamente o droit de saisine e as regras de capacidade sucessória do artigo 1.798 é indevidamente prestigiar a legislação ordinária em detrimento da norma constitucional. Por fim, interditar o chamamento sucessório na RAPM com base em razões de segurança jurídica é uma violação ao princípio da proporcionalidade: ao realizar essa ponderação de interesses, por mais que o intérprete ou o legislador quisessem prestigiar a estabilidade das relações, jamais poderiam o fazer em detrimento do núcleo essencial do direito à herança da prole postumíssima. Por todas essas razões, acreditamos que prevalece o chamamento à sucessão dos filhos concebidos postumamente. 


\section{CONCLUSÃO}

No presente trabalho, investigamos a atribuição de direitos sucessórios aos filhos concebidos a partir de reprodução assistida post mortem. Depreendemos que a literatura especializada se divide em quatro correntes principais. Em primeiro lugar, observamos que há aqueles que negam peremptoriamente a herança à prole postumíssima, alegando falta de capacidade sucessória e/ou a segurança jurídica de quem foi chamado à sucessão no momento do falecimento do doador do material genético. Notamos que essa corrente peca por dar atenção demais às normas infraconstitucionais, em detrimento do direito fundamental à herança, e por anacronicamente adotar o pensamento oitocentista que prefere o seguro ao justo.

Em segundo lugar, analisamos a corrente doutrinária que sustenta a necessidade de vocação testamentária para que a prole postumíssima receba direitos hereditários. Percebemos que tais argumentos são insuficientes, notadamente porque a vocação testamentária recebe uma proteção normativa inferior à legítima, o que criaria descendentes de segunda categoria. Além disso, compreendemos que seria um contrassenso subordinar o direito sucessório de filhos à elaboração de testamento no Brasil, onde é notório o fato de que o brasileiro não testa.

Em terceiro lugar, estudamos a corrente doutrinária que tenta condicionar o chamamento sucessório da prole postumíssima à realização da concepção dentro de um "prazo de espera". Percebemos que os prazos sugeridos - em especial aquele previsto no artigo 1.800 para o chamamento por testamento da prole eventual de terceiros - são inaplicáveis por analogia à RAPM, notadamente por terem ratios diferentes da ora discutida.

Em quarto lugar, discorremos sobre a vocação legítima da prole postumíssima, independentemente de prazo de realização do procedimento ou de chamamento testamentário. Concluímos que se trata da solução mais compatível com a dimensão objetiva do direito fundamental à herança, em especial sua força normativa, o dever estatal de sua efetivação, e a proibição de sua proteção deficiente.

\section{REFERENCIAS}


ALMEIDA, José Luiz Gavião de. Código Civil Comentado: direito das sucessões, sucessão em geral, sucessão legítima: Artigos 1.784 a 1.856, Volume XVIII. São Paulo: Atlas, 2003.

ALMEIDA JUNIOR, Jesualdo Eduardo de. Técnicas de reprodução assistida e o biodireito. São Paulo: Revista dos Tribunais, 2005.

ANDRADE, José Carlos Vieira de. Os direitos fundamentais na Constituição portuguesa de 1976. $2^{\mathrm{a}}$ ed. Coimbra, PT: Almedina, 2001.

ANDRADE, Ana Carolina Souza. A Sucessão Legítima do Filho Concebido após a Morte do Pai. 2007. Monografia (Especialização) - Curso de Preparação à Magistratura, Escola de Magistratura do Paraná; Curitiba, 2007.

BERALDO, Anna de Moraes Salles. Consequências jurídicas da reprodução humana assistida post mortem. Revista do Programa de Pós-Graduação em Direito da Universidade Federal da Bahia, n. 20. Salvador: Universidade Federal da Bahia, 2010.

CARDIN, Valéria Silva Galdino; CAMILO, Andryelle Vanessa. Dos aspectos controvertidos da reprodução assistida post mortem. Revista de Ciências Jurídicas da UEM, v.7, n.1, jan/jun 2009. Maringá: Universidade Estadual de Maringá, 2009.

COCO, Bruna Amarijo. Reprodução assistida post mortem e seus aspectos sucessórios. Texto incluído em maio de 2012. Disponível em: http://jus.com.br/956642-bruna-amarijococo/publicacoes\#ixzz3JwPDIqTt. Acesso em 03 de novembro de 2014.

DE LUCA, Caterina. O concebido post mortem no Direito das Sucessões. Texto incluído em 2010. Disponível em:

http://www.emerj.tjrj.jus.br/paginas/trabalhos_conclusao/2semestre2010/trabalhos_22010/cat erinaluca.pdf. Acesso em 09 de outubro de 2014.

DELGADO, Mário Luiz. Os direitos sucessórios do filho havido por procriação assistida, implantado no útero após a morte de seu pai. Revista Jurídica Consulex, Editora Consulex, Ano VIII, ${ }^{\circ} 188,2004$.

DIAS, Maria Berenice. Manual das Sucessões. 3. Ed. São Paulo: Revista dos Tribunais, 2013.

DINIZ, Maria Helena. O estado atual do biodireito. São Paulo: Saraiva, 2007.

GAMA, Guilherme Calmon Nogueira da. Filiação e reprodução assistida: introdução ao tema sob a perspectiva do direito comparado. Revista Brasileira de Direito de Família, n.5, abr./maio/jun./2000.

GAMA, Guilherme Calmon Nogueira da. A nova filiação: o biodireito e as relações parentais. Rio de Janeiro: Renovar, 2003. 
GOMES, Felipe Lima. O direito fundamental à herança: âmbito de proteção e consequências de sua constitucionalização. Tese (Doutorado) - Universidade Federal do Ceará, Faculdade de Direito, Programa de Pós-Graduação em Direito, Fortaleza, 2015.

HENRIQUES, Fernanda de Borges. A repercussão da reprodução assistida post mortem e o direito de herança. Disponível em: http:// www3.pucrs.br/pucrs/files/uni/poa/direito/graduacao/tcc/tcc2/trabalhos2009_1/fernanda_henr iques.pdf. Acesso em 14 de novembro de 2014.

HIRONAKA, Giselda Maria Fernandes Novaes. A incessante travessia dos tempos e a renovação dos paradigmas: a família, seu status e seu enquadramento na pós-

modernidade. Revista da Faculdade de Direito, Universidade de São Paulo, [S.1.], v. 101, p. 153-167, jan. 2006. ISSN 2318-8235. Disponível em:

http://www.revistas.usp.br/rfdusp/article/view/67702. Acesso em 19 de novembro de 2015.

HIRONAKA, Giselda Maria Fernandes Novaes. As inovações biotecnológicas e o direito das sucessões. Revista Jurídica: órgão nacional de doutrina, jurisprudência, legislação e crítica judiciária. Ano 57, no 375, janeiro de 2009. Porto Alegre: Notadez, 2009.

KRELL, Olga Jubert Gouveia. O direito fundamental à reprodução humana assistida no Brasil e suas repercussões na filiação civil: uma abordagem de lege ferenda. Tese (Doutorado em Direito) - Centro de Ciências Jurídicas da UFPE. Recife: Universidade Federal de Pernambuco, 2005.

LEITE, Eduardo de Oliveira. Bioética e presunção de paternidade (considerações em torno do art. 1.597 do Código Civil). LEITE, Eduardo de Oliveira (Coord.) Grandes temas da atualidade: bioética e direito. Rio de Janeiro: Forense, 2004.

LIMA JUNIOR, Daniel Verissimo de. Reflexos da Inseminação Artificial Homóloga Post Mortem no Âmbito do Direito Sucessório. Texto incluído em 2012. Disponível em: http://jus.com.br/artigos/23960/reflexos-da-inseminacao-artificial-homologa-post-mortem-noambito-do-direito-sucessorio\#ixzz2ck2MaQM3. Acesso em 21 de julho de 2013.

MACHADO, Maria Helena. Reprodução Humana Assistida: aspectos éticos e jurídicos. Curitiba: Juruá, 2009.

MADALENO, Rolf. Curso de direito de família. $5^{\text {a }}$ ed. rev. e ampl. Rio de Janeiro: Forense, 2013.

MAXIMILIANO, Carlos. Hermenêutica e aplicação do direito. $8^{\mathrm{a}}$ ed. Rio de Janeiro: Freitas Bastos, 1965.

MELLO, Celso Antônio Bandeira de. O conteúdo jurídico do princípio da igualdade. $3^{\mathrm{a}}$ ed, $20^{a}$ tiragem. São Paulo: Malheiros, 2011.

MONTALBANO, Ana Caroline Oliveira. Inseminação Post Mortem e Seus Reflexos no Direito de Família e Sucessões. Revista da ESMEC, v.19, n.23. Florianópolis: Escola Superior da Magistratura do Estado de Santa Catarina, 2012. 
MOREIRA FILHO, José Roberto. Os novos contornos da filiação e dos direitos sucessórios em face da reprodução humana assistida. Texto incluído em 30 de agosto de 2011. Disponível em: http://direitouemt1.wordpress.com/2011/08/30/11/> Acesso em 14 de novembro de 2014.

PASSOS, Ana Maria Maciel Bittencourt. Direito à filiação e inseminação post mortem: uma solução à luz do direito positivo brasileiro. 2009. Dissertação (Mestrado) Universidade Federal da Bahia, Faculdade de Direito, 2009.

PEREIRA, Caio Mário da Silva. Instituições de direito civil, v.5. Direito de Família. $16^{\mathrm{a}}$ ed. rev. e atual. de acordo com o Código Civil de 2002 por Tânia da Silva Pereira. Rio de Janeiro: Forense, 2007.

PRESOT, Regiane Sousa de Carvalho. Inseminação Artificial Post Mortem: Efeitos no Direito Sucessório. Disponível em: http://www.academia.edu/1802155/Inseminacao_Artifi cial_Post_Mortem_Efeitos_no_Direito_Sucessorio. Acesso em 21 de juho de 2013.

QUEIROZ, Juliane Fernandes. Paternidade: aspectos jurídicos e técnicas de inseminação artificial. Belo Horizonte: Del Rey, 2001.

RIGO, Gabriella Bresciani. O Status de Filho Concebido Post Mortem Perante o Direito Sucessório na Legislação Vigente. Portal Jurídico Investidura, Florianópolis/SC, 08 Jul. 2009. Disponível em: http://investidura.com.br/biblioteca-juridica/obras/monografias/3849. Acesso em 23 de novembro de 2014.

SARLET, Ingo Wolfgang. A eficácia dos direitos fundamentais: uma teoria geral dos direitos fundamentais na perspectiva constitucional. 12. ed. rev. atual e ampl. Porto Alegre: Livraria do Advogado Editora, 2015.

SCALQUETTE, Ana Claudia Silva. Estatuto da reprodução assistida. 2009. Tese (Doutorado em Direito Civil) - Faculdade de Direito, Universidade de São Paulo, São Paulo, 2009. Disponível em: http://www.teses.usp.br/teses/disponiveis/2/2131/tde-08032010095921/. Acesso em 29 de setembro de 2014.

SCHNEIDER, Caroline; SARTORI, Ellen Carina Mattias. Das consequências sucessórias da concepção post mortem: o direito fundamental à herança e o princípio da segurança jurídica. Trabalho publicado nos Anais do XXIV Congresso Nacional do CONPEDI, realizado em Belo Horizonte - MG em novembro de 2015.Disponível em: http://www.conpedi.org.br/publicacoes/66fsl345/rlmau22a/439K5ezeKI4U1y1c.pdf. Acesso em 06 de abril de 2016.

SIMÃO, José Fernando; TARTUCE, Flavio. Direito Civil, v. 6: Direito das Sucessões. 6. ed. rev. e atual. Rio de Janeiro: Forense; São Paulo: Método, 2013.

VENOSA, Silvio de Salvo. Direito Civil: direito de família. 7. ed. São Paulo: Atlas, 2007. 